\title{
Construction of maps for soil recycling in regional infrastructural works integrating soil-quality laws
}

\author{
F. van Lienen ${ }^{1}$, G. Frapporti ${ }^{2} \&$ A. Stein ${ }^{3}$ \\ ${ }^{1}$ Corresponding author; IWACO, Consultants for water and Environment, P.O. Box 8520, \\ 3009 AM ROTTERDAM, the Netherlands; e-mail: f.lienen@rtd.iwaco.nl \\ 2 IWACO, Consultants for water and Environment, P.O. Box 8520, 3009 AM \\ ROTTERDAM, the Netherlands; e-mail: g.frapporti@rtd.iwaco.nl \\ ${ }^{3}$ Agricultural University Wageningen, Dept. of Environmental Sciences, P.O. Box 37, \\ 6700 AA WAGENINGEN, the Netherlands; e-mail: alfred.stein@bodlan.beng.wau.nl
}

Manuscript received: 15 September 1998; accepted in revised form: 15 June 2000

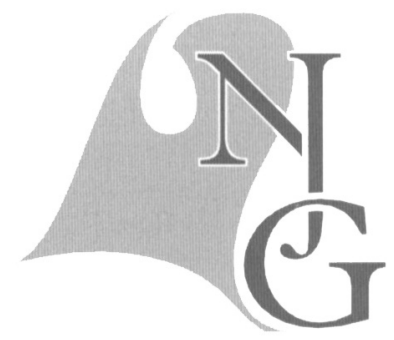

\begin{abstract}
A soil-quality map is at present an important tool to integrate laws on soil quality with regional infrastructural works. Basic data are commonly available, but soil quality is an indicator that has to be derived from these data, including site-specific environmental standards. We propose three geostatistics-based methods for the comparison of interpolated contaminant concentrations and standards.

The study is illustrated by data from a part of the Betuwe railroad transect, which extends over $12 \mathrm{~km}$ in the western Netherlands. As it turns out, a useful procedure is to combine interpolated contaminant concentrations with interpolated threshold values.
\end{abstract}

Keyzoords: geostatistics, infrastructural works, soil-quality maps

\section{Introduction}

A full overview of the chemical quality of soils is required for the incorporation of restrictions set by environmental laws in infrastructural work planning, urban development, remediation and nature-reserve development. Constructed soil-quality maps differ, however, from mapped contaminant concentrations. These concentrations need to be assessed for their toxicity or natural background levels. In most countries, criteria have been defined in laws. Environmental judgement declares soils 'clean' or 'polluted' and whether they are suitable for specific purposes. Criteria such as clay content or organic-matter content, as well as the concentration of the contaminant, are incorporated in this judgement, to estimate toxicity and to correct for variation in natural soil composition. Mapped concentrations must be compared to environmental thresholds to evaluate soil quality.
Many studies have been carried out in the past on spatial variability of environmental contaminants. A full overview, also in a broader context, wa provided by Burrough (1993). So far, combining environmental concentrations with environmental thresholds has been addressed by using probabilities of exceeding, or by using conditional simulations (Van Groenigen et al., 1997). Thresholds are now being defined in a site-specific setting, and - because data availability is necessarily limited - integrated means of spatial interpolation are increasing in importance.

The present contribution aims to bridge the gap between mapping of raw concentration data and soilquality maps reflecting the judgement of these concentrations. The conversion of 'raw' concentration data into soil-quality maps is illustrated by a study on the planning of a new railroad track. Emphasis is put on the approach to incorporate additional criteria for mapping, rather than on applied statistical methods. 


\section{Environmental thresholds}

All western countries use standards to judge and maintain the quality of soil. In the Netherlands, two laws have been created for the environmental judgement of soil composition: the Act of Building Material (ABM), and the Act of Soil Protection (ASP). The $A B M$ regulates the re-use of soil and soil displacement when used as building material, whereas the ASP regulates the judgement of quality of soil that remains in situ. The soil quality is measured relative to standards or thresholds.

Both laws define thresholds for many contaminants. The ASP and the ABM use the same threshold values, but subsequent judgement is different and relates to different purposes of soil. Three threshold values, i.e., standards to determine the level of soil contamination and soil quality, can be distinguished: the target threshold (S), the halfway threshold (T) and the intervention threshold (I). Natural background values are defined as below $S$; T divides lightly polluted from moderately polluted soil; and soil with concentrations of contaminants above I is qualified for remediation. The thresholds depend (linearly) on the clay and/or organic-matter contents of the soil and are defined for all elements individually (Table 1 ).

\section{A case study: the Sophia track of the Betuwe railroad}

The future Betuwe railroad is an entirely new railroad that transects the Netherlands and will be used to transport goods from the port of Rotterdam to Germany's major industrial area, the Ruhr area, from 2003 onwards. Part of the railroad track, the Sophia track, is investigated in the present contribution. The Sophia track has a width of less than $100 \mathrm{~m}$ and a length of approx. $12 \mathrm{~km}$, and is situated in the west-

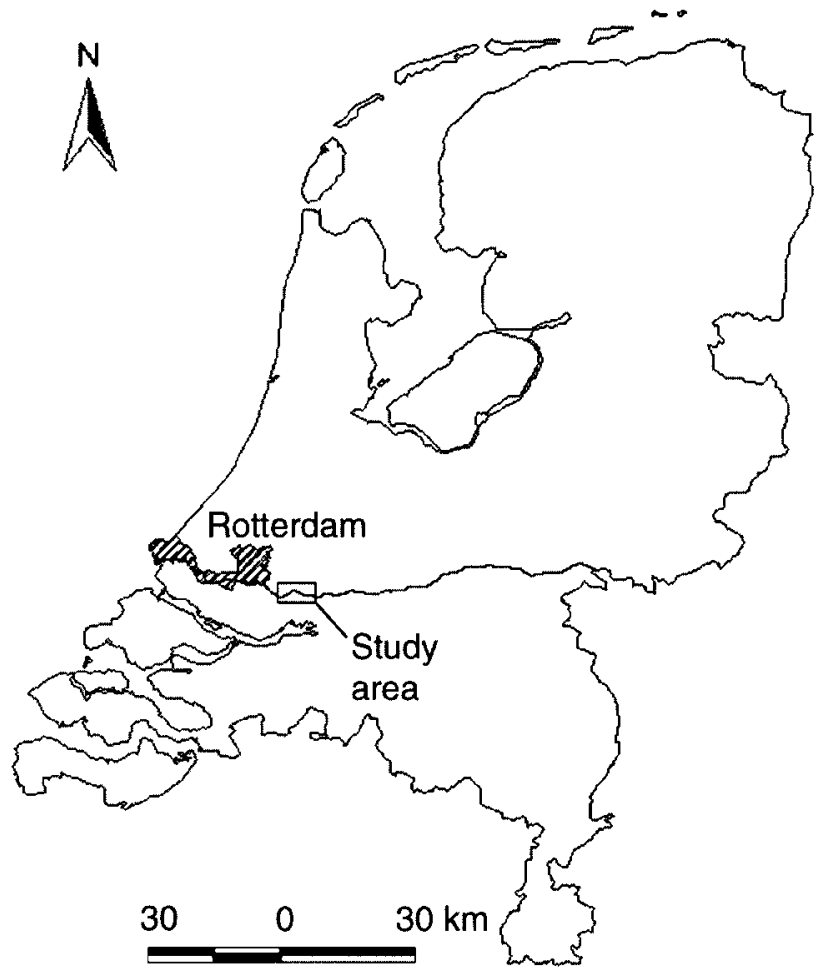

Fig. 1. Location of the Betuwe railroad (bold line) and the Sophia track (square).

ern part of the Betuwe railroad (Figs. 1-2). The subsoil of the Sophia track consists of Holocene sediments: marine clay, fluvial clay, and peat. The topographic relief is about $2 \mathrm{~m}$, with peats situated in the lower areas covered with a fluvial clay layer of varying thickness. More nearby the river, the upper clay layer is thicker and the layer rich in organic matter is absent.

Land use in this rural area is mainly grassland $(40 \%)$ on marine clay. Arable land covers $16 \%$ of the area, and $5 \%$ of the area is covered by forest. Horticulture in greenhouses covers $9 \%$. Almost the entire Sophia polder (the island in the centre of the river) is

Table 1. Act of Building Material (ABM) and Act of Soil Protection threshold-calculation equations.

\begin{tabular}{llll}
\hline & target threshold $(\mathrm{S})$ & halfway threshold $(\mathrm{T})$ & intervention threshold $(\mathrm{I})$ \\
\hline $\mathrm{As}$ & $15+0.4 \cdot(\mathrm{L}+\mathrm{H})$ & $1.3 \cdot(15+0.4 \cdot(\mathrm{L}+\mathrm{H}))$ & $1.9 \cdot[15+0.4 \cdot(\mathrm{L}+\mathrm{H})]$ \\
$\mathrm{Cd}$ & $0.4+0.007 \cdot(\mathrm{L}+3 \cdot \mathrm{H})$ & $1.5 \cdot[0.4+0.007 \cdot(\mathrm{L}+3 \cdot \mathrm{H})]$ & $15.3 \cdot[0.4+0.007 \cdot(\mathrm{L}+3 \cdot \mathrm{H})]$ \\
$\mathrm{Cr}$ & $50+2 . \cdot \mathrm{L}$ & $3.8 \cdot(50+2 \cdot \mathrm{L})$ & $3.8 \cdot(50+2 \cdot \mathrm{L})$ \\
$\mathrm{Cu}$ & $15+0.6 \cdot(\mathrm{L}+\mathrm{H})$ & $2.9 \cdot[15+0.6 \cdot(\mathrm{L}+\mathrm{H})]$ & $5.3 \cdot[15+0.6 \cdot(\mathrm{L}+\mathrm{H})]$ \\
$\mathrm{Hg}$ & $0.2+0.0017 \cdot(2 \cdot \mathrm{L}+\mathrm{H})$ & $1.1 \cdot[0.2+0.0017 \cdot(2 \cdot(\mathrm{L}+\mathrm{H})]$ & $33.1 \cdot\{0.2+0.0017 \cdot[2 \cdot(\mathrm{L}+\mathrm{H})]\}$ \\
$\mathrm{Pb}$ & $50+\mathrm{L}+\mathrm{H}$ & $2.4 \cdot(50+\mathrm{L}+\mathrm{H})$ & $6.2 \cdot(50+\mathrm{L}+\mathrm{H})$ \\
$\mathrm{Ni}$ & $10+\mathrm{L}$ & $1.7 \cdot(10+\mathrm{L})$ & $6 \cdot(10+\mathrm{L})$ \\
$\mathrm{Zn}$ & $50+1.5 \cdot(2 \cdot \mathrm{L}+\mathrm{H})$ & $1.9 \cdot[50+1.5 \cdot(2 \cdot \mathrm{L}+\mathrm{H})]$ & $5.1 \cdot[50+1.5 \cdot(2 \cdot \mathrm{L}+\mathrm{H})]$ \\
\hline
\end{tabular}

Units are in $\mathrm{mg} @ \mathrm{~kg}^{-1}$ dry matter.

$\mathrm{H}(=o)$ :organic matter content in mass $\%$ of dry matter; $\mathrm{L}(=l)$ : clay content $(<2 \mu \mathrm{m})$ in mass $\%$ of dry matter.

The ABM minimum and maximum values of organic matter content are $2 \%$ and $30 \%$, respectively.

Soil-quality categories: clean $\left(\mathrm{G}_{1}\right): y<\mathrm{S}$; lightly polluted $\left(\mathrm{G}_{2}\right): \mathrm{S}<y<\mathrm{T}$; moderately polluted $\left(\mathrm{G}_{3}\right)$ : T $<y<\mathrm{I}$; remediation: $y>\mathrm{I}$. In addition leachability standards may be taken into account; these are not incorporated in this table. 
covered by grassland and was, until recently, a floodplane of the river where sediments were deposited. Some local pollution is present, caused by small-scale industry.

\section{Sampling methods}

The area is divided into locations, based on ownership-boundary maps. The actual sampling and analysis took place from 1993 to 1996 , according to protocol NVN 5740 for explorative soil and groundwaterquality research (NNI, 1991). Analyses were carried out according to the NEN (the Dutch equivalent of ISO) 5770,5759 and 6426 standards (NNI, 1993, 1994, 1995). The NVN 5740 protocol takes into account the set-up of a sampling design, the sampling strategy (i.e., number and size of the samples), requirements for combining subsamples into mixed samples (number of subsamples) and the method of analysis of the samples. The NVN 5740 protocol allows mixed samples to be taken from the upper layer, $0-0.5 \mathrm{~m}$ below the soil surface. The number of subsamples of the mixed sample depends upon the area of the location. Point samples were occasionally also taken, i.e., when the measured value of the mixed sample exceeded the $T$ threshold. The samples have been analysed for $\mathrm{As}, \mathrm{Cd}, \mathrm{Cr}, \mathrm{Cu}, \mathrm{Hg}, \mathrm{Ni}, \mathrm{Pb}$ and $\mathrm{Zn}$ concentrations, for their amounts of organic matter and clay, and for dry-matter content.

Mixed and point samples are not commonly used in combination with each other in geostatistical mapping. This has two reasons: (1) mixed samples average concentrations of 4 or 5 subsamples and therefore have a lower variance than point samples; (2) the variation between samples at small distances, which are required to describe spatial dependence, is lost or neglected at the local scale level when using mixed samples. The variance between point samples at small distances is therefore used in the present contribution to estimate the variance within the distance range of mixed samples. The minimum distance of sampling is approx. $5 \mathrm{~m}$.

In total, 232 mixed samples were selected for mapping of the soil quality. Point samples were also included, if not taken from sites with obvious local pollution. The total number of samples analysed for heavy metals varies from 92 for As up to 312 for $\mathrm{Pb}$. Clay and organic-matter content have been analysed in one sample per location. These contents were assigned to all the observation points at the same site. When different soil types occurred at a site, the procedure was repeated. The clay and organic-matter contents were determined for 258 observations.

\section{Mapping of soil quality}

\section{Geostatistics and soil-quality maps}

Spatial variation complicates both an accurate description of the soil quality and straightforward calculation of the soil volume for remediation or recycling. Geostatistical methods use the spatial dependence of soil characteristics and of heavy-metal concentrations, and may result in better estimates. Use of geostatistics has the advantage that spatial variability can be visualised and quantified in probability maps of soil quality. It is in particular useful if many samples are available for an accurate estimate of the soil quality.

To present a soil-quality map of a contaminant element, its concentrations must be compared to the environmental threshold values. Various techniques for this comparison are illustrated in Figure 2 for the mapping cadmium; they will be explained below. Final soil-quality maps are demonstrated in Figure 3; they incorporate $\mathrm{ABM}$ and ASP laws and supervise soil transfer and recycling, combining all (contaminant) elements. These maps will be referred to further on as the 'zone maps', with mapped zones that give an overview of the environmental soil quality and the allowed transfers of soil within or between the zones.

\section{Stratification}

Stratification is carried out to construct maps of the heavy-metal, organic-matter and clay content. By stratifying the area, the accuracy of the predicted values is expected to increase, because the variability per stratum is expected to be smaller (Stein et al., 1988; Brus \& De Gruijter, 1993). Stratification is based on five categories of strata: urban area, fluvial clay, marine clay, peat, and the Sophia-polder island. Stratification was tested for significance by a one-way ANOVA in mean values of heavy-metal, organic-matter and clay content. Residuals, $\hat{\varepsilon}_{i}$, are used for interpolation, by subtracting $\hat{\mu}_{i}$, the geometric mean of a concentration in the stratum to which the ith observation belongs, from the observed contents $y_{i} i=1$..n:

$\hat{\varepsilon}_{i}=y_{i}-\hat{\mu}_{i}$

\section{Geostatistical method}

The geostatistical method applied in this study consists of six steps, based upon either individual measurements, $y_{i}$, or residuals, $\hat{\varepsilon}_{i}$. The six steps are:

1. determination of the distribution and log transformation,

2. calculation of the variogram, 
A
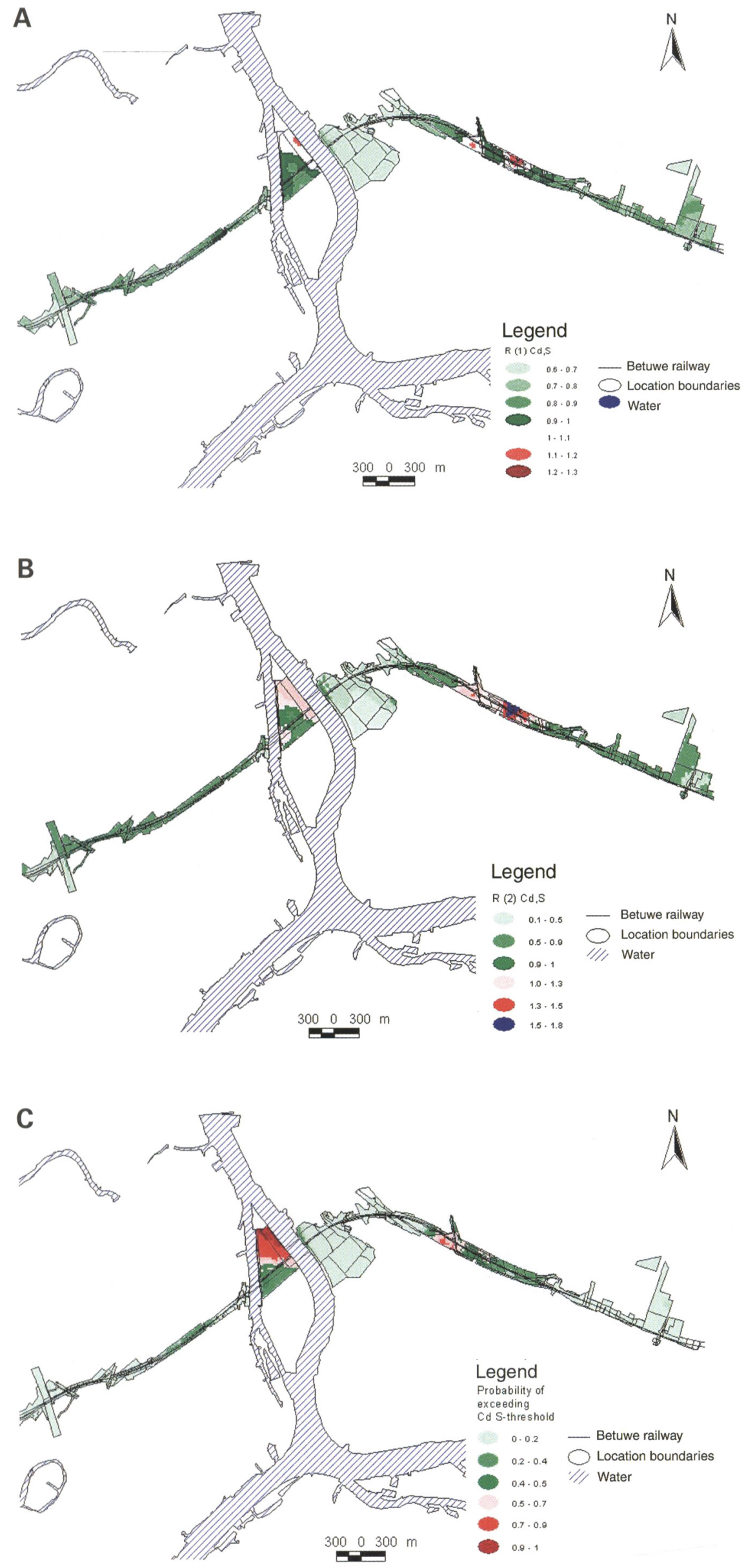

Fig. 2. Soil-quality maps for cadmium.

A: based upon kriged ratios, $\mathbf{R}^{(1)} \mathrm{Cd,S}$.

$B$ : based upon ratios of kriged contents and kriged thresholds, $\mathbf{R}^{(2)}{ }_{C d, S}$.

C: probability map of exceeding the $\mathrm{S}$ threshold. 

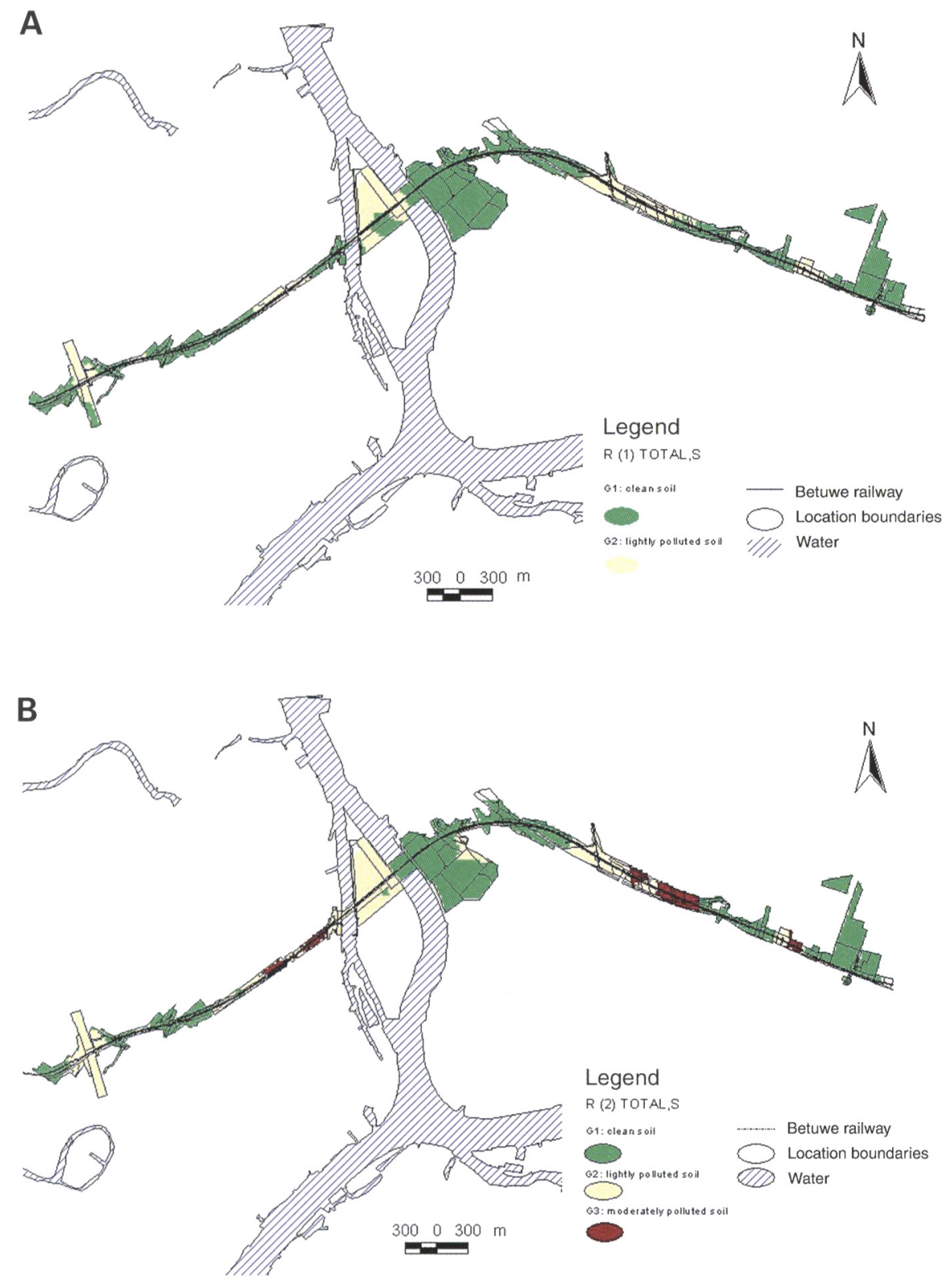

C

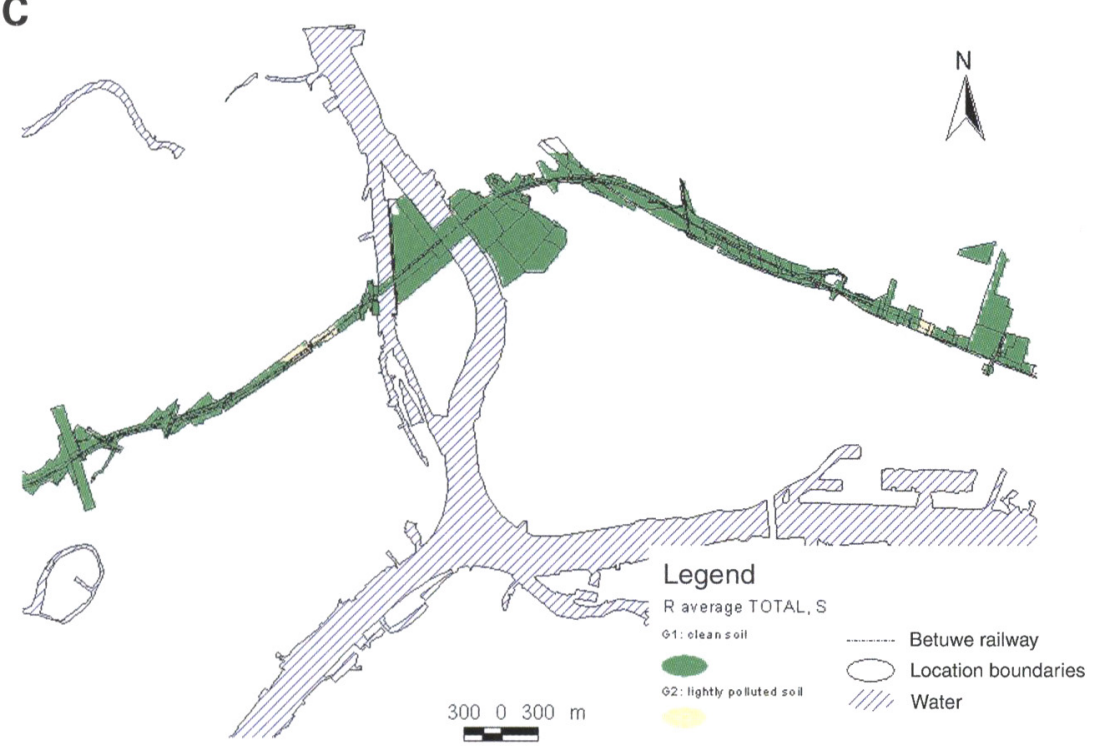

Fig. 3. Overall soil-quality maps.

A: based upon joining kriged ratios, $\mathbf{R}^{(1)}$ Total,s.

B: based upon joining ratios of kriged contents and kriged thresholds, $\mathrm{R}^{(2)}$ TOTAL,, .

C: probability map of exceeding the $S$ threshold. 
3. determination of the size of the prediction unit for kriging,

4. kriging,

5. preparation of maps of probabilities of exceeding threshold values,

6. preparation of maps of threshold ratios.

\section{Determination of the distribution and log transformation}

The observed concentrations need to have a specified distribution to allow probabilistic statements. The normal distribution is of particular use. Log-transformed concentrations were used for $\mathrm{Cd}, \mathrm{Cu}, \mathrm{Hg}, \mathrm{Pb}$, $\mathrm{Zn}$ and organic matter, because visual inspection of histograms showed a normal distribution after log transformation.

\section{Calculation of the variogram}

Variograms were determined for the observed contents of heavy metals, $y_{i}$, clay, $l_{i}$, and organic matter, $o_{i}$, or of their residuals, $\hat{\varepsilon}_{i}$.

Determination of the size of the prediction unit for kriging The size of the prediction unit is determined by the minimum practical soil volume, i.e. related to soil transport units, being as close as possible to the amount of material that can be transported by trucks. This corresponds to a grid cell of $25 \times 25 \times 1 \mathrm{~m}^{3}=625$ $\mathrm{m}^{3}$. Too few sample pairs were available, however, to estimate the variogram accurately within $25 \mathrm{~m}$ (being the minimum distance between the mixed samples), so that additional sampling was carried out. An additional sampling of 32 point samples was carried out following NVN 5740 (NNI, 1991), with sampling pairs at distances less than $5 \mathrm{~m}$. The initial high nugget effects of the variogram models were thus reduced and most variogram model fits showed an improvement.

\section{Kriging}

Concentrations of the heavy metals, organic matter and clay content are predicted using ordinary point kriging. Mixed samples are considered being represented by the average coordinates at the centre of the subsamples. In case of stratification, the mean of the stratum is added to the kriged residual for all residuals separately:

$y^{\star}{ }_{i}=\hat{\mu}_{i}+, \varepsilon^{\star}{ }_{i}$

in which formula:

$\varepsilon^{\star}{ }_{i}$ is the kriged residual,

$\hat{\mu}_{i}$ is the geometrical mean of a concentration within the stratum to which the $i^{\text {th }}$ observation belongs, $y^{\star}{ }_{i}$ is the estimated concentration.
A similar formula was used to estimate the organic matter content, $o^{\star}{ }_{i}$, and the clay content, $l^{\star}{ }_{i}$.

The threshold for cadmium was calculated for each grid cell individually and is therefore a site-specific threshold. Kriged residuals of organic matter and clay content were combined according the formula in Table 1 to calculate these site-specific thresholds. With these calculations, excess kriged metal content over the standard was calculated in several ways, as will be discussed in the two following subsections.

\section{Preparation of maps of probabilities of exceeding threshold values}

One of the aims of a soil-quality map is to help minimise the risk of rejecting 'clean soil' as polluted or accepting 'polluted soil' as clean when soil transfers take place. To assess this risk, indicator kriging was used to assess the probability of exceeding a threshold value.

The heavy metal-contents were transformed into complementary indicator variables, $i_{k}$, without stratifying the area. For this transformation, the environmental thresholds are used as cut-off values. The cut-off values, $c u t_{k}$, are defined equal to the $\mathrm{S}, \mathrm{T}$ or I thresholds if $k$ equals 1,2 and 3 , respectively. For example, in the $x^{\text {th }}$ observation point, $x, i_{k}(x)=1$, if $y_{i} \geq$ cut $_{k}$; otherwise $i_{k}(x)=0$.

Contrary to indicator kriging maps that show the probability of not exceeding a threshold, complementary indicator maps show for a grid cell the probability of exceeding a threshold. A probability of 1 indicates exceeding of the threshold with probability 1 ; likewise, a probability of 0 indicates clean soil (probability of not exceeding a threshold) with probability 1 . Figure $2 \mathrm{c}$ shows, as an example, such a map for the probability of cadmium exceeding $c u t_{1}$ (the $S$ threshold).

\section{Preparation of maps of threshold ratios}

The degree to which a threshold is exceeded is also important if one wishes to distinguish polluted areas from their surroundings. This applies in particular to the $S$ threshold, which is the threshold that distinguishes between 'polluted' and 'non-polluted', but can be replaced by other threshold ( $T$ or $I$ ) values as well. The ratio value is the ratio between the observed heavy-metal concentration and the $S$ threshold calculated from observed clay and organic-matter content:

$R_{y, S}^{(1)}=y / S(o, l)$

in which formula $y$ is the observed concentration and $S(o, l)$ is the $S$ threshold calculated from observed organic matter, $o$, and clay contents, $l$. The $R_{y, S}^{(1)}$ ratio equals 1 if the concentration is equal to the $S$ threshold; it is below 1 if $y$ is below the $S$ threshold and 
above 1 if $y$ exceeds the $S$ threshold. Maps of the ratio values of heavy-metal concentrations and the $S$ threshold were constructed by kriging. These maps quantify soil quality therefore in terms of the $S$ threshold.

At several locations, no clay or organic-matter measurements were available. As an alternative, we also kriged the metal concentrations, the organic-matter and clay content separately, and combined the ratios afterwards. Subsequently a ratio map was constructed by dividing the predicted concentration by the predicted specific threshold, calculated from predicted organic-matter and clay contents:

$R^{(2)}{ }_{y, S}=y^{\star} / S\left(o^{\star}, l^{\star}\right)$

in which formula $y^{\star}$ is the kriged concentration and $S\left(o^{\star}, l^{\star}\right)$ is the $\mathrm{S}$ threshold calculated from the kriged organic matter content, $o^{\star}$, and the clay content, $l^{\star}$. Notice that both levels are site specific and that $R^{(2)}$ depends upon the stratum to which the location belongs. We have, for reasons of transparency, not included this dependence into the equations.

\section{Results}

\section{Soil-quality maps per heavy metal}

For each heavy metal, three maps were produced (Fig. 2):

- a probability map of exceeding the $S$ threshold (step 5);

- a map of the kriged ratios of the observed metal over the $\mathrm{S}$ treshold based on observed organicmatter and clay content $\left(R_{y, S}^{(1)}\right)$ (step 6);

- a map of the ratios of the kriged concentrations over the kriged $\mathrm{S}$ thresholds $\left(R^{(2)}{ }_{y, S}\right)$ (step 6).

For some combinations of heavy metals and threshold values, a probability map could not be made. When there were too few instances of the threshold being exceeded, the variogram of the indicator values could not be estimated. Indicator kriging maps could be calculated for $\mathrm{Cd}, \mathrm{Ni}, \mathrm{Zn}$ against $c u t_{1}$ and for $\mathrm{Cd}$ against $\mathrm{cut}_{2}$.

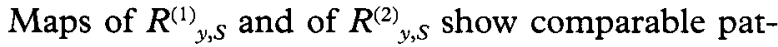
terns that were similar to those on the probability maps of the various heavy metals. The main difference between the maps is that the maxima of $R_{y, S}^{(1)}$ are lower, and that the minima are higher than those for $R_{y, S}^{(2)}$

\section{Cross-validation}

A cross-validation was applied to check the difference between the maps. In cross-validation, one sample is left out in turn and a value is predicted with kriging at that location. This prediction is compared to the observed threshold. In general, we observed that the mean errors of the difference between estimated and observed values were positive, and highest for $\mathrm{Pb}$ and $\mathrm{Zn}$, indicating an overestimation of the actual concentrations. Organic-matter and clay content, $\mathrm{Cr}$ and $\mathrm{Ni}$ were underestimated. The ratio parameters were also overestimated, in particular $\mathrm{Pb} / \mathrm{S}$ and $\mathrm{Zn} / \mathrm{S}$.

The 32 samples collected during the additional survey could also be used for validation, as they were used only for improving the variogram, not for kriging. Moreover, the ratios were taken independently from the samples to validate $R_{y, S}^{(1)}$ and $R_{y, S}^{(2)}$ estimates. Both $R_{y, S}^{(1)}$ and $R_{y, S}^{(2)}$ overestimate observed ratios for all heavy metals (Table 2). The $R^{(2)}{ }_{y, S}$ estimate shows smaller deviations for most parameters. $\mathrm{As}, \mathrm{Cr}$ and $\mathrm{Ni}$ are estimated accurately for ${R^{(2)}}_{y, S}$ but $\mathrm{Cd}, \mathrm{Cu}, \mathrm{Hg}, \mathrm{Pb}$ and $\mathrm{Zn}$ show larger deviations from the observed ratio, comparable to $R_{y, s}^{(1)}$. High standard deviations are caused by the limited number of additional non-mixed samples.

\section{The final soil-quality map}

The individual heavy-metal maps need to be combined into one overall measure of soil quality to assess the soil quality for all parameters. The final soil-quality maps or zone maps were not made by indicator kriging because not all parameters were measured in all samples. We therefore made the soil-quality maps joining the individually kriged heavy-metal maps. The two alternatives, $R_{y, S}^{(1)}$ and $R^{(2)}$,S , were used (Fig. 3).

The predicted ratios for all metals were added for each grid cell and the grid cell was allocated to clean soil (category $\mathrm{G}_{1}$ ) if all ratios $R^{(1)}{ }_{y, s}$ were below 1 . If at least one of the metals exceeded the $S$ threshold, but was lower than the $T$ threshold, the grid cell was allocated to lightly polluted soil (category $\mathrm{G}_{2}$ ). No kriged ratios were higher than the $\mathrm{T}$ threshold, so that no

Table 2. Mean and standard deviation of the differences of 32 additional samples from the kriged estimates for $\mathbf{R}^{(1)}{ }_{y, S}$ and $\mathbf{R}^{(2)}{ }_{y, S}$.

\begin{tabular}{lllll}
\hline heavy metal & $\mathrm{R}^{(1)}{ }_{y, s}$ & & $\mathrm{R}^{(2)}{ }_{y, s}$ & \\
\hline & mean & std. dev. & mean & std. dev. \\
& & & & \\
$\mathrm{As}$ & -0.09 & 0.1 & -0.05 & 0.1 \\
$\mathrm{Cd}$ & -0.45 & 0.2 & -0.44 & 0.4 \\
$\mathrm{Cr}$ & -0.26 & 0.1 & 0.01 & 0.1 \\
$\mathrm{Cu}$ & -0.22 & 0.2 & -0.37 & 0.7 \\
$\mathrm{Hg}$ & -0.48 & 0.1 & -0.29 & 0.2 \\
$\mathrm{Ni}$ & -0.07 & 0.2 & -0.02 & 0.1 \\
$\mathrm{~Pb}$ & -0.43 & 0.2 & -0.43 & 0.5 \\
$\mathrm{Zn}$ & -0.38 & 0.2 & -0.56 & 0.6 \\
& & & & \\
\hline
\end{tabular}


moderately polluted soils $\left(G_{3}\right)$ were mapped. The same procedure was used for the $R^{(2)}{ }_{y, S}$ maps, but in this case the $\mathrm{T}$ threshold was exceeded (for $\mathrm{Cd}$ ) and several grid cells were allocated to moderately polluted soil (category $\mathrm{G}_{3}$ ).

\section{Decisions-support-system model}

Soil-quality maps are used to incorporate soil-quality laws in soil handling and transport in construction works. Until now, environmental law was not emphasised, and only physical soil characteristics for construction (sand, for instance, is a stronger supporting soil than peat) and transport distance were of importance. Adding soil-quality constraints to the construction of infrastructural works, decisions on transport, re-use and applicability of soil become more complex. Therefore the need for a decision-support system (DSS) was investigated.

The DSS combines the soil-quality estimates of the 25 by $25 \mathrm{~m}$ grid cell, together with information on construction characteristics of soil and the civil-technical design. To design optimum soil logistics (transport, re-use, stock piles) that minimise costs, transport prices are calculated and prices are assigned to the grid cells depending on their soil quality; clean soil, for instance, is credit for USD 10, while polluted soil costs USD 20 to dispose of. The constraints are set by law and may involve limitations on the application of polluted soil in unpolluted areas.

\section{Discussion}

We compared soil-contaminant concentrations to site-specific threshold values. This concept has been worked out using ratio values (Lamé et al., 1997). The variogram model estimated for ratio variables is a variogram of the combination of three spatial variables (contaminant, clay and organic-matter concentration) with different spatial dependencies. Therefore, the spatial model used for a combination of these three variables cannot be the optimum model. When ratio values are calculated using three variables that are kriged individually and thus require three variograms, there will, however, be three prediction errors instead of one. Further research is needed to investigate how the errors of the three estimates are related to the errors resulting from the interpolation based on a less accurate model.

The accuracy of the grid-cell estimate is of special interest if the maps are used to estimate volumes of soil for different categories of soil quality. The $R_{y, s}^{(1)}$ and $R^{(2)}{ }_{y, S}$ maps are validated by comparing the estimates with additional sampling results. The $R_{y, S}^{(2)}$ ap- proach is more accurate and is therefore to be preferred, despite effects of stratification and of combining three kriging errors. The $R_{y, S}^{(1)}$ map shows a smaller range of ratio values for each individual contaminant than the comparable $R^{(2)}{ }_{y, S}$ map, as moderately contaminated G3 soil does not occur on the $R^{(1)}$ y,S maps, but does occur on the $R_{y, S}^{(2)}$ maps. This can be explained by the different data-manipulation procedures: the $R^{(2)}{ }_{y, S}$ maps use log-transformed data and stratification (residuals are kriged), whereas $R_{y, S}^{(1)}$ is calculated by dividing two estimates. The larger range of ratios in the $R_{y, S}^{(2)}$ maps influences the zones of the soil-quality map. The $R_{y, S}^{(1)}$ map of soil quality shows only two categories: clean and lightly polluted soil, whereas also a moderately polluted soil-quality category appears on the $R_{y, S}^{(2)}$ map.

The stratification is based on soil type and built-on area. The values of the strata may show different concentration levels but the explained variance is low (less than 50\%). The stratification influences the mapping, however, because the mean of the stratum adds more to the final estimate than do the variations in kriged residuals.

The three approaches to translate soil-content values into soil quality yielded, as a ruke, the same soilquality map. All three maps indicate the same areas that exceed the $S$ threshold. If the maps are used to provide a general impression on soil quality in an area, all approaches seem comparably accurate.

The ABM states that, if only one metal exceeds the $S$ threshold, the category of soil quality is changed from 'clean soil' ( $G_{1}$ category) into 'lightly polluted soil (G2). This may cause the rejection of large soil volumes for specific use. Statistical theory (Gilbert, 1987) implies that the more parameters are tested, the greater the probability that one of the parameters will exceed its threshold, especially if the parameters show no correlation. The soil-quality maps therefore depend upon the number of soil contaminants incorporated. The number of parameters to be measured is not yet given in the ABM and ASP.

Several scenarios are proposed to compensate for this effect. One of the scenarios it to average the ratios of the metals (Lamé et al., 1997). A (small) exceeding of the $S$ threshold is compensated by other metal concentrations below the $S$ threshold in the same sample. The average ratio is kriged in Figure $3 \mathrm{c}$. The areas were the estimated ratio exceeds 1 is strongly diminished, and the soil-quality map yields a larger area of clean soils by using the average ratio. The geostatistical approach therefore visualises easily the results of different soil-quality judgement scenarios. How many elements - and which elements - may be compensated (and up to which values) remains a political and medical issue. 


\section{Conclusions}

We propose to 'translate' contaminant concentrations, clay and organic-matter content of individual samples into site-specific soil quality - denoted by the ratio of concentrations to thresholds - to judge soil quality by classifying soil-contaminant concentrations into suitability classes. Kriged ratios result in a soilquality map. An alternative is to krige contaminant concentrations, organic-matter and clay content separately, followed by calculation of the ratio using a threshold based upon kriged estimates. The present study shows that the second method gave the most reliable results for the area under investigation. Kriged maps often overestimate the observed quality because many variables are log-normally distributed. The soilquality maps show therefore more areas exceeding the standards than will be encountered in practice.

Soil quality maps can be supported by actual application of a quantitative environmental-pollution analysis in infrastructural works as presented here. A full spatial overview of the soil quality forms the basis for soil-transport scenarios, and hence the need for additional soil-quality studies. Other criteria, like physical suitability of soil, costs and transport distance (logistics), can be joined with soil-quality criteria in a decision-support system. The kriged maps form one of the inputs of this system.

\section{Acknowledgements}

We are grateful to B. Satijn from NOK.D and J.W. van Groenigen at the ITC, Enschede, for fruitful dis- cussions in various stages of this research. The NS (Dutch Railroad Company) provided the data.

\section{References}

Brus, D.J. \& De Gruijter, J.J., 1993. Design-based versus model-based estimates of spatial means; theory and application in environmental soil science. Environmetrics 4: 123-152.

Burrough, P.A.B., 1993. Soil variability: a late $20^{\text {th }}$ century view. Soils and Fertilizers 56:529-562.

Gilbert, R.O., 1987. Statistical methods for environmental pollution monitoring. Van Nostrand Reinhold (New York): 320 pp.

Lamé, F.P.J., Leenaers, H., Satijn, B. \& Frapporti, G., 1997. Toetsen aan de streefwaarde. Internal Report TNO-MEP (Apeldoorn) R97/474; Internal Report IWACO (Rotterdam) 1069130 (for NOVEM, Utrecht): $28 \mathrm{pp}$.

NNI (Nederlands Normalisatie-Instituut), 1991. Onderzoeksstrategie bij verkennend onderzoek. NNI (Delft) NVN 5740: $36 \mathrm{pp}$.

NNI (Nederlands Normalisatie-Instituut), 1993. Bodem en slib; Monstervoorbehandeling van grond en slib voor de bepaling van elementen met atomaire-spectrometrie; Ontsluiting met salpeterzuur en zoutzuur in een microgolfoven. NNI (Delft) NVN 5770: 4 pp.

NNI (Nederlands Normalisatie-Instituut), 1994. Bodem; Bepaling van het gehalte aan kwik in grond met atomaire-bsorptiespectrometrie (koude damptechniek) na ontsluiting met salpeterzuur en zoutzuur. NNI (Delft) NEN 5779: 7 pp.

NNI (Nederlands Normalisatie-Instituur), 1995. Water; Bepaling van 40 elementen met behulp van atomaire-mmissiespectrometrie met inductief gekoppeld plasma. NNI (Delft) NEN 6426: 8 pp.

Stein, A., Hoogerwerf, M.R. \& Bouma, J, 1988. Use of soil-map delineation to improve ( $\mathrm{co}-$ ) kriging of point data on moisture deficits. Geoderma 43: 163-177.

Van Groenigen, J.W., Stein, A. \& Zuurbier, R., 1997. Optimization of environmental sampling using interactive GIS. Soil Technology 10: 83-98. 